\title{
LEGISLAÇÃO DE ENSINO DA PÓS-GRADUAÇÃO LATO SENSU NA MODALIDADE À DISTÂNCIA: INSTRUMENTOS DE DOMINAÇÃO
}

\section{LEGISLATION FOR LATO SENSU GRADUATE COURSES IN THE DISTANCE EDUCATION MODALITY: TOOLS OF DOMINATION}

\author{
Ana Lúcia da Silva ${ }^{1}$ \\ Sueli Maria de Araujo Cavalcante ${ }^{2}$ \\ Valeria Maria Pereira Santos ${ }^{3}$
}

\section{RESUMO}

Trata-se de um estudo exploratório de natureza qualitativa, objetivando analisar os instrumentos de dominação presentes na legislação da especialização lato sensu na modalidade à distância, como forma de auxiliar nas reflexões sobre a hierarquização das relações - a dominação como principal elemento de poder, bem como os elementos constitutivos na autoridade legal (norma). É uma releitura dos textos legais com dois objetivos: primeiro, contextualizar a especialização lato sensu na modalidade à distância no cenário legislativo do país e segundo, deflagrar os instrumentos de dominação presentes na especialização lato sensu na modalidade à distância. A legislação de ensino, seja, ela do ensino da especialização lato sensu à distância ou de qualquer nível e modalidade, por si, já é um forte instrumento de dominação, por tratar da normatização de um campo de poder - a Educação. Nesse campo de poder, são introduzidos, via legislação, os genuínos instrumentos do poder simbólico e hierárquico, uma das formas de dominação. São eles: unidade escolar, gestão democrática, projeto político pedagógico, coordenação pedagógica, corpo docente e normas escolares, entre outros.

PALAVRAS-CHAVE: Especialização Lato Sensu; Instrumentos de Dominação; Normatização.

\begin{abstract}
This qualitative and exploratory study analyses the tools of domination within the legislation for lato sensu graduate courses in the distance education modality in order to have support to reflect on the hierarchization of relationships - domination as the main element of power, and

\footnotetext{
${ }^{1}$ Graduada em Pedagogia pela Faculdade Dom Aureliano Matos em 1889, especialista em Direito Educacional pela Faculdade Internacional Signorelli (2013) e Mestranda em Políticas Públicas e Gestão da Educação Superior/UFC. Experência com o magistério no Ensino Infantil; Fundamental ( com todas as disciplinas de $1^{\mathrm{a}}$ a $4^{\mathrm{a}}$ série e de $5^{\mathrm{a}}$ a $8^{\mathrm{a}}$ série, com Língua Portuguesa, Matemética; Ensino Médio, nas disciplinas pedagógicas do curso de Magistério (antigo $2^{\circ}$ grau profissionalizante); Ensino Superior ( História da Educação, Psicologia da Educação, Sociologia da Educação). Atualmente sou Técnica em Assuntos Educacionais lotada na Divisão de Formação Profissional-PROGEP/UFC.

${ }^{2}$ Doutorado em Educação Brasileira pela Universidade Federal do Ceará (UFC) e Mestre em Engenharia de Sistemas e Computação pela Universidade Federal do Rio de Janeiro (UFRJ). Graduada em Processamento de Dados pela UFC e em Administração de Empresas pela Universidade Estadual do Ceará (UECE). Atualmente é Professora Associada da UFC e Professora efetiva do Mestrado Profissional de Políticas Públicas e Gestão da Educação Superior - POLEDUC. Vice-Coordenadora e Professora do Curso de Administração Pública, na Educação à Distância, pela UFC e Universidade Aberta do Brasil - UAB.

${ }^{3}$ Graduada em Pedagogia Pela Universidade Federal do Acre, Especialista em Pedagogia Gestora pelas Faculdades Integradas de Várzea Grande. Experiência no Sistema Penitenciário do ACRE: como pedagoga e diretora de Unidade Sócio-Educativa em Rio Branco/Ac; Pedagoga na Unidade Penitenciária Feminina de Rio Branco/Ac; Coordenadora de projetos de capacitação de presos no Instituto de Administração Penitenciária de Rio Branco/Ac; Gerente da Escola de Administração Penitenciária no Instituto de Administração Penitenciária de Rio Branco/Ac, Ouvidora do Sistema Penitenciário no Instituto de Administração Penitenciária de Rio Branco/Ac.
} 
shaping elements of the legal authority (norm). It is a rereading of legal texts with two goals: firstly, to contextualize the lato sensu graduate courses in the distance education modality within the Brazilian legislative panorama, and secondly to expose the tools of domination within the legislation for lato sensu graduate courses in the distance education modality. Teaching legislation, whether for lato sensu graduate courses in the distance education modality or for any other level or modality of education, it is, by itself, already a strong tool of domination because it concerns the normalization about a power field - the Education. Within this power field are inserted, via legislation, genuine tools of symbolic and hierarchic power, one of the methods of domination, which are: school unity, democratic management, pedagogical-political project,pedagogical management, faculty, and school rules, amongst others.

Key words: Lato sensu graduate course; Tools of Domination; Normalization.

\section{INTRODUÇÃO}

Diante do crescimento em alta velocidade da Educação à Distância (EAD) no país, a base legal que regula tal modalidade de ensino vem se tornando um universo de inesgotável fonte de investigação, principalmente pela diversidade das normas: instruções normativas, notas técnicas, portarias normativas, pareceres, resoluções, decretos, leis e outros documentos que têm força de lei como, Plano Nacional de Educação, referenciais curriculares, referenciais de educação, Projeto Político pedagógico, entre outras.

Alguns pesquisadores como Alves (2009), Lessa (2011), Miguel (2004), Preti (2009), Salvucci, Lisboa e Mendes (2012), Slavov e Slavov (2010), Valle e Souza (2011), Vianner, Barcia e Luz (2001), têm estudado a legislação da EAD sob diferentes perspectivas, seja na perspectiva da legislação como fonte de estudo da educação brasileira (MIGUEL, 2004), seja avaliando as reflexões da legislação na EAD (LESSA, 2011), ou buscando compreender seus fundamentos legais (SALVUCCI, LISBOA, MENDES, 2012), entre outros.

Para esses autores a legislação do país, é rígida, descontínua e esparsa, cujos dispositivos legais impõem à EAD as mesmas exigências do ensino presencial. Enquanto este já tem uma legislação consolidada, aquela ainda funciona sob a égide de decretos e portarias.

O passado histórico da política educacional brasileira para a EAD traz momentos de rupturas abruptas e descontínuas. Já que a mesma avoca em seu cerne o projeto político do governo em vigência, portanto centra-se na orientação política do próprio Ministério da Educação - MEC, como representante e intérprete das ideias dominantes e impostas por organismos internacionais. São projetos concebidos para uma realidade idealizada por órgão e organismos internacionais, desfalcados de elementos práticos e da realidade concreta para os 
quais se destinam. Daí vem à inadequação dos currículos, cursos e materiais didáticos padronizados e programas desarticulados com as características regionais dos alunos ou com suas necessidades concretas de ensino. (KENSKI, 2010, p.9)

Salvucci, Lisboa e Mendes (2012) avaliam que, no Brasil, a legislação vigente da EAD limita o crescimento desse modelo nas instituições de ensino superior, principalmente no que se refere aos cursos de graduação à distância. No entendimento desses autores, é inadequado estabelecer as mesmas exigências do modelo presencial ao modelo de EAD, desconsiderando as diferenças entre os dois modelos. Na mesma esteira, no estudo da legislação da EAD feito por Lessa (2011), a política brasileira de regulação da EAD é avaliada como incipiente e em formação.

Segundo Vianner, Barcia e Luz (2001), as novas tecnologias propiciaram mudanças na EAD, mas em contra partida, a legislação brasileira não andou no mesmo ritmo dessas mudanças. As instituições enfrentam grandes desafios para conseguirem autorização e credenciamento, as exigências são as mais variadas: infraestrutura (prédio, pólo, equipamentos, outros), capacitação de recursos humanos (administrativo, tutor, coordenação pedagógica), recursos didático-pedagógicos, entre outras.

Valle e Souza (2011) chamam atenção para o fato das políticas públicas circunscreverem em simples emissão de leis e regulamentos, desconsiderando que a realidade educacional é um movimento vivo, tratando-se de uma prática social. Assim a concepção de política pública não se encerra e nem se limita a emissão de textos legais, reduzindo o campo educacional ao simplório espaço de aplicação de leis e de regulamentos, de teorias, métodos e procedimentos definidos. As autoras reafirmam que a lei limita e inibe a autonomia das Instituições de Educação Superior - IES, ao apresentar uma série de determinação quanto ao processo pedagógico, prescrevendo procedimentos a serem seguidos.

Há entre os autores retrocitados, uma convergência de pensamento sobre o engessamento legal proporcionado pelo modelo presencial para nortear a EAD.

Tomando-se, especificamente, como ponto de partida os instrumentos de dominação presentes na legislação que regulamenta a Especialização Lato Sensu na modalidade à distância, verifica-se o Poder, a dominação, seja pela imposição efetiva do resultado desejado, seja pela realização espontânea, tendo em vista a superioridade de quem o exerce.

Este trabalho objetiva, portanto, analisar os instrumentos de dominação presentes na legislação da especialização lato sensu (EAD), considerando a hierarquização das relações - no sistema de ensino (órgão central e o sistema de ensino nacional e os subsistemas, 
estadual e municipal com suas unidades educacionais). Para isso, o estudo se baseia no disciplinamento expresso no caput dos artigos $8^{\circ}, 9^{\circ}$ e 80 da lei $n^{\circ}$. 9.394/96 da Lei de Diretrizes e Bases da Educação Nacional - LDB (BRASIL, 1996) e nos Referenciais de Qualidade para a Educação Superior a Distância - RQESAD (BRASIL, 2007).

Considera-se relevante o desvelamento dos instrumentos de dominação que permeiam os textos legais como forma de auxiliar nas reflexões sobre a hierarquização das relações - subsidiadas pelos conceitos bourdieusianos de campo, habitus, poder simbólico sendo retroalimentados pelo poder legal (norma).

\section{NORMAS EAD E ESPECIALIZAÇÃO LATO SENSU À DISTÂNCIA}

A especialização lato sensu à distância ainda não dispõe de um corpo sólido de normas, as mesmas estão dispersas no corpo de diretrizes referentes ao ensino à distância e ensino presencial. Apesar de não ter uma trajetória normativa própria, a modalidade aos poucos se faz presente no normativo educacional do país, sendo o Decreto-Lei No 236/67 (BRASIL, 1967) traz alterações no Código Brasileiro de Comunicação (CBC) que regulavam os serviços da radiodifusão e televisão educativa, uma das primeiras normas a mencionar experiência em EAD em nosso país e, finalmente, vem a LDB conferir status de modalidade de ensino à educação à distância.

A legislação de ensino presencial é extensa e sólida. Apesar de espessa, a legislação brasileira até hoje é marcada pela fragmentação, principalmente visível na quantidade de normas editadas, bem como pela grande quantidade de normas revogadas. Enquanto esta já tem uma legislação consolidada, a especialização lato sensu à distância funciona sob a égide de decretos e portarias, cujo foco é o ensino à distância, com raríssima exceção: como é o caso do Parecer CFE N 891/1980 (BRASIL, 1980), o mesmo autorizava um programa piloto de especialização lato sensu à distância sob o comando da Associação Brasileira de Tecnologia Educacional - ABT, e a Resolução CNE/CES No 1/2007 (BRASIL, 2007) que disciplina a oferta de cursos de especialização lato sensu, seja presencial ou em EAD.

Ressaltamos que a fragmentação é uma característica da política de regulação do ensino brasileiro, não se trata apenas de uma modalidade, mas se revela em todas modalidades e níveis. Logo, reflete também na edição de normas para a especialização lato sensu à distância.

Dentro desse contexto legislativo encontram-se os RQESAD (BRASIL,2007), trazendo parâmetros para a modalidade. Mesmo não tendo força de lei, trata-se de um 
documento norteador tanto para as IES como para os órgãos normalizadores e fiscalizadores, no que tange ao atendimento das exigências colocadas pelo documento, funciona como cartilha das IES e dos órgãos fiscalizadores.

A partir das citações referentes à política de regulação (norma), é notório que houve um significativo avanço da legislação da EAD após o advento da LDB, principalmente quando se leva em conta o período anterior à LBB/96, cuja oferta de curso de especialização lato sensu a distância dependia de uma autorização especial dada pelo MEC (Ministério de Educação), já que não havia uma regulamentação voltada para essa modalidade de ensino.

\section{METODOLOGIA}

Este estudo caracteriza-se como pesquisa exploratória, de natureza qualitativa, uma vez que se propõe a investigar as dimensões subjetivas dos atos de dominação presentes nos textos legais acerca da especialização lato sensu (EAD). Foi desenvolvido através de pesquisa bibliográfica e documental, ou seja, baseou-se em leituras e consultas a livros, entendimentos doutrinários, legislação e artigos, além das normas que disciplinam o Ensino à Distância e os Referenciais de Qualidade para a Educação Superior à Distância (RQESAD/2007), lançado pelo Ministério da educação (MEC/2007). Sabe-se que os RQESAD não são exatamente uma lei, porém é aceito no ordenamento legal vigente, como cartilha para as IES e os órgãos fiscalizadores.

Para a análise dos dados utilizou-se a perspectiva da análise de conteúdo de Bardin (2006), com auxílio da análise temática, por melhor adequação com a questão central e possibilitar maior interação do objeto/problema com o pesquisador, na busca da construção dos caminhos epistemológicos possíveis com o material coletado.

\section{INSTRUMENTOS DE DOMINAÇÃO NA LEGISLAÇÃO LATO SENSU À DISTÂNCIA À LUZ DE PIERRE BOURDIEU}

Na linha de construção de caminhos epistemológicos busca-se inspiração e fundamentação teórica, no pensamento de Pierre Bourdieu sobre instrumentos de dominação, sendo essencial para construção de inferências e suscitar respostas ao problema levantado. Corrobora no entendimento do pensamento bourdieusiano sobre os instrumentos de dominação os autores como, Almeida (2005), Bertolleti (2010), Canesin (2002), Pena (2012), Pies (2011), Rosendo (2009), entre outros. 
Dialogando com instrumentos de dominação presente na legislação lato sensu à distância destacam-se os conceitos bourdieusianos de campo, habitus, campo de poder $e$ poder simbólico.

Bourdieu (1989) usa a palavra campo para designar o espaço em que se desenrola as lutas de classes e também as lutas pela hegemonia de concepções ideológicas, seja de cunho social, político, econômico, entre outras. Não é um espaço físico, mas um espaço simbólico, com fronteiras invisíveis, cujo embate se dar no silêncio com o consentimento do outro. Há na sociedade uma grande diversidade de campos, e dentre estes há aqueles que se destacam como campo de poder. Assim, campo de poder está relacionado com o poder, a força que o mesmo tem sobre os demais, como é o caso do campo jurídico que dita as leis, o campo político que conduz as politícas para o bem estar e desenvolvimento social, o campo educacional, entre outros. O habitus é o que vai sendo incorporando à experiência do indíviduo ao longo da vida, é inerente ao campo em que o mesmo está inserido.

Dentro do campo, o principal instrumento é o poder simbólico atribuindo a certos agentes, que por sua vez, está ligado a relação entre dominante e dominado, cuja premissa baseia-se na aceitação de inferioridade do dominado e no reconhecimento da superioridade do poder e do capital simbólico atribuido ao dominante, de modo que essa relação tem toda aparência de natural, sem que, o dominado tome consciência da dissimulação da violência simbólica por traz dessa pretensa naturalidade (Bourdieu, 1989).

Os dados foram organizados conforme as cinco fases de análise de conteúdo de Moraes (1999), que são: (1) preparação; (2) unitarização ou transformação do conteúdo em unidades; (3) categorização; (4) descrição e (5) interpretação.

\section{Quadro 1 - Fases da Análise de Conteúdo}

\begin{tabular}{|c|c|}
\hline Unidades de Registro & Unidades de Contexto \\
\hline Escola e legislação & \multirow{3}{*}{$\begin{array}{l}\text { Sistema de Ensino } \\
\text { (abordado na perspectiva dos art. } \\
8^{\circ}, 9^{\circ} \text { e } 80 \text { da atual LBB) }\end{array}$} \\
\hline Autoridade e gestão escolar & \\
\hline Hierarquia & \\
\hline Estrutura político-pedagógico: & \multirow{5}{*}{$\begin{array}{l}\text { Processo Pedagógico } \\
\text { (abordado na perspectiva dos } \\
\text { RQESAD/2007) }\end{array}$} \\
\hline Professor-conteudista & \\
\hline Professor-tutor & \\
\hline Aluno & \\
\hline Conteúdo/material didático & \\
\hline Campo & \multirow{4}{*}{$\begin{array}{l}\text { Processo de dominação } \\
\text { (abordado na perspectiva do } \\
\text { pensamento bourdieusiano) }\end{array}$} \\
\hline Habitus & \\
\hline Campo de poder & \\
\hline Poder simbólico & \\
\hline
\end{tabular}

Fonte: elaborado pelas autoras. 
O Quadro 1 traz a demarcação das fronteiras usadas na categorização de cada unidade de contexto. Têm-se três grupos de contextos, sendo que o terceiro é essencial para promover o dialogo com as demais unidades. Portanto, a unidade categorizada de processo de dominação é a grande unidade de construção do entendimento da legislação da especialização lato sensu a distancia.

Podemos afirmar que a legislação de ensino, assim também, com as normas da especialização lato sensu à distância, expressam o poder burocrático e hierárquico, logo, inegavelmente se traduz num campo de poder.

Para caracterizar o marco legal desse estudo apresenta-se no quadro em destaque os artigos que marcam essa fronteira delimitada pelos artigos, $8^{\circ}, 9^{\circ}$ e 80 da LDB e suficientes para expressar o poder dentro do campo da política de regulação.

\section{Quadro 2 - Marco legal dos cursos de especialização lato sensu - Sistema de Ensino}

\begin{tabular}{|l|l|}
\hline Unidade de Contexto & $\begin{array}{l}\text { Documento 1- Lei de diretrizes e Bases da Educação Nacional (Lei } \\
\mathbf{n}^{\mathbf{0} 9.394 / 96)}\end{array}$ \\
\hline Sistema de Ensino & $\begin{array}{l}1.1 \text { Art. } 8^{\circ} \text {. A União, os Estados, o Distrito Federal e os Municípios } \\
\text { organizarão, em regime de colaboração, os respectivos sistemas de } \\
\text { ensino. } \\
1.2 \mathrm{O} \text { art. } 9^{\circ} \text { rege as competências da União referentes à elaboração do } \\
\text { Plano Nacional de Educação, criação dos órgãos de controle do ensino, } \\
\text { assistência técnica, autorizar, reconhecer, credenciar, supervisionar e } \\
\text { avaliar instituições e cursos, processo de avaliação dos sistemas de } \\
\text { ensino, entre outras. (síntese do artigo) } \\
1.3 \text { Art. 80 O Poder Público incentivará o desenvolvimento e a } \\
\text { veiculação de programas de ensino a distância, em todos os níveis e } \\
\text { modalidades de ensino, e de educação continuada. }\end{array}$ \\
\hline
\end{tabular}

Fonte: elaboradas pelas autoras.

A atual LDB ao conceber um sistema de poder alicerçado no sistema político de distribuição de competências entre os entes federados, conferindo a União o poder máximo para delinear a Política Nacional de Educação, põe em destaque a norma com sendo um dos principais instrumentos para assegurar as relações de poder.

$\mathrm{O}$ art. $8^{\circ}$ exprimi um complexo sistema de repartição de competências que abrangem as esferas federal, estadual e municipal, são os subsistemas que integram o Sistema de Ensino Nacional, tendo o MEC como grande emanador das normas gerais de ensino. Cada ente federado (União, Estado e Municípios) atua prioritariamente em um nível de ensino, com poder de editar normas complementares na sua área de competência e criar seus órgãos disciplinadores como: Ministério de Educação e Conselho Nacional de Educação (órgãos 
federais), Secretarias Estaduais e Conselhos Estaduais de Educação (órgãos estaduais) e Secretarias Municipais e Conselhos Municipais de educação (órgãos municipais), entre outros.

$\mathrm{O}$ art. $9^{\circ}$ dar continuidade à complexa repartição do poder no campo da política de regulação, elegendo a União com a expertise de formular, fiscalizar e avaliar a política de ensino do país. Assim a legislação federal confere poder jurisdicional aos sistemas dos estados e municípios e os mesmos habilitam o funcionamento de suas unidades de ensino, que por sua vez regula seus processos internos. Registre-se que a norma gera uma cadeia de comando (poder) que vai se afunilando até a sala de aula (aluno), independente de sua esfera física ou virtual.

Acrescente à cadeia de comando a interpretação do poder simbólico na ótica de cada agente escolar (gestores dos sistemas de ensino e das instituições escolares, equipe pedagógica, corpo docente e discente), assim capturar o processo de dominação trazido no texto da norma por si só não faz sentido, já que a mesma ganha resignificação a partir do habitus trazido e incorporado por cada agente que atua dentro do campo educacional. A norma tanto modula o habitus, como o assegura, seja por introduzir preceitos e procedimentos, seja pelo capital simbólico que diferencia os agentes e do poder de conversão que os mesmos representam no interior desse campo.

Não há determinismo no campo, mas um movimento dialético de agente e entre os agentes. Cabe dizer que para Bourdieu, campo de poder não é sinônimo de campo político.

Campo de poder [...] é o espaço de relações de forças entre os diferentes tipos de capital ou, mais precisamente, entre os agentes suficientemente providos de mais de um dos diferentes tipos de capital para poderem dominar o campo correspondente e cujas lutas se intensificam sempre que o valor relativo dos diferentes tipos de capital é posto em questão [... ] (BOURDIEU, 1996, p. 52)

O pensamento bourdieusiano provoca reflexão sobre o sistema educacional e o papel imprescindível de cada agente (habitus de cada um) no funcionamento desse campo. Lembrando que os sujeitos envolvidos nesse processo formam uma cadeia de relações (teia), cada um com sua subjetividade, motivações, cultura, logo seria ingenuidade, considerá-los como simples recipientes (receptáculos, depósitos) e que a simples presença de instrumentos favoráveis à dominação seja um processo passivo de assimilação.

A dominação não é o efeito direito e simples da ação exercida por um conjunto de agentes ("a classe dominante") investidos de poderes de coerção, mas o efeito indireto de um conjunto complexo de ações que se engendram na rede cruzada de limitações que cada um dos dominantes, dominado assim pela estrutura do campo através do qual se exerce a dominação, sofre de parte de todos os outros. (BOURDIEU, 1996, p.52, grifo nosso) 
A legislação da especialização lato sensu em EAD é enquadrada no campo da política de regulação de ensino, de modo que, há nele um jogo de forças impulsionado pela concepção política vigente e pelos ideais de educação almejados pela sociedade, influenciando diretamente no conteúdo da norma e na concepção de ensino vigente.

Esse jogo de forças traz em si o poder simbólico e burocrático, uma vez que a norma institui organização e autoridade (burocrática) aos sistemas de ensino, seus órgãos, instituições escolares e aos processos escolares (o fazer pedagógico) que acontecem no interior da unidade escolar.

Recorre-se à Bourdieu na interpretação de Canesin (2002) Pies (2011), Rosendo (2009) para explicar os conceitos básicos e essenciais de campo e habitus.

Canesin (2002) ao estudar o conceito de habitus da teoria bourdieusiana destaca que a formação do habitus deve ser levada em conta alguns aspectos, como a relação a partir de um grupo ou classe social (campo), as representações que vão sendo construídas segundo as significações pessoais de cada um e também do posicionamento em relação ao grupo e a sociedade em geral.

Seguindo essa linha de pensamento Pies (2011) destaca a formação do habitus como processo histórico e prático em que as experiências passadas ganham resignificação no presente no processo de interação social.

Assim o habitus é apresentado como produto da história, que produz práticas
individuais e coletivas (superação do subjetivismo e do objetivismo), e produz
história em conformidade com os esquemas por ela engendrados. Evidencia-se,
dessa forma, uma estreita relação entre habitus e história, pois ao mesmo tempo em
que o habitus é entendido como produto da história, ele produz história. (PIES,
2011, p.45)

Canesin (2002) ao interpretar o conceito de campo da teoria bourdieusiana, caracteriza como sendo o espaço, o lugar em que se processam as lutas de classes, no qual o posicionamento do indivíduo é pré-estabelecido na estrutura social, seja do campo ou na própria sociedade. Cada campo é singular com relações específicas de poder e dentro de cada grupo as relações são antagônicas, pois, de um lado, o dominado e, do outro, o dominante.

Canesin (2002) continua dizendo que as estruturas de cada campo são homogêneas e com especificidades que lhe são próprias, que por sua vez vão de encontro ao ideário imaginado pelos agentes do grupo. Porém, o indivíduo pode atuar em diversos campos, nos quais suas ações e práticas sociais serão legitimadas conforme a especificidade e poder simbólico do seu capital. Vale ressaltar que a hierarquia não funciona apenas em um 
campo especifico, há hierarquia entre os diversos agentes e entre os diversos grupos, sendo que o diferencial está intimamente ligado ao poder simbólico de cada um.

Bourdieu e Passeron apud Pena (2012) também ver a escola como o "lócus da violência simbólica". A escola revela-se como sendo o local apropriado a "reprodução das estruturas sociais", ou seja, cabe a ela promover a "reprodução do macro no micro", cujo papel do indivíduo institucionalizado é assimilar e reproduzir a sociedade dentro do sistema escolar.

Segundo Botler (2010) o Sistema de Ensino Brasileiro é pautado na hierarquia, seja ela na concepção de divisão das competências dos entes federados, seja do ponto de vista dos órgãos reguladores, seja na estrutura organizacional escolar e no processo ensino aprendizagem. Essa estrutura hierarquizada está fundamentada na estrutura do poder vigente que determina e dá sustentação e legitima a autoridade disciplinar dento da escola.

Seguindo com a categorização:

\section{Quadro 3 - Marco legal dos cursos de especialização lato sensu - Processo Pedagógico}

\begin{tabular}{|c|c|}
\hline $\begin{array}{l}\text { SEGUNDA UNIDADE } \\
\text { DE CONTEXTO }\end{array}$ & $\begin{array}{l}\text { Documento } 2 \text { - Os Referenciais de Qualidade de Educação para a } \\
\text { Educação à Distância - RQEEAD }\end{array}$ \\
\hline Processo Pedagógico & $\begin{array}{l}\text { 2.1 Estrutura Pedagógica } \\
\text { 2.1.1 Projeto Político Pedagógico } \\
\text { O projeto político pedagógico deve apresentar claramente sua opção } \\
\text { epistemológica de educação, de currículo, de ensino, de aprendizagem, de perfil } \\
\text { do estudante que deseja formar; com definição, partir dessa opção, de como se } \\
\text { desenvolverão os processos de produção do material didático, de tutoria, de } \\
\text { comunicação e de avaliação, delineando princípios e diretrizes que alicerçarão } \\
\text { o desenvolvimento do processo de ensino e aprendizagem. (RQESAD, 2007, } \\
\text { p.8), } \\
\text { 2.1.2Organização Didático-Pedagógica } \\
\text { Esta dimensão contempla os seguintes aspectos: } \\
\text { a) aprendizagem dos estudantes; } \\
\text { b) práticas educacionais dos professores e tutores; } \\
\text { c) material didático (seus aspectos científico, cultural, ético, estético, didático- } \\
\text { pedagógico e motivacional, sua adequação aos estudantes e às tecnologias de } \\
\text { informação e comunicação, sua capacidade de comunicação etc.) e às ações dos } \\
\text { centros de documentação e informação (midiatecas); } \\
\text { d) currículo (sua estrutura, organização, encadeamento lógico, relevância, } \\
\text { contextualização, período de integralização, dentre outros); } \\
\text { e) sistema de orientação docente e à tutoria (capacidade de comunicação } \\
\text { através de meios eficientes; de atendimento aos estudantes em momentos à } \\
\text { distância e presenciais; orientação aos estudantes; avaliação do desempenho } \\
\text { dos estudantes; avaliação de desempenho dos professores e tutores; avaliação } \\
\text { dos polos de apoio presencial). } \\
\text { [...] } \\
\text { (RQEEAD, 2007, p.17 e 18, grifo nosso) }\end{array}$ \\
\hline
\end{tabular}

Fonte: elaborado pelas autoras. 
Visualiza-se por meio do quadro 3 em destaque, que o processo pedagógico complementa o entendimento do refinamento dos instrumentos da cadeia de comando categorizados no quadro 2.

No rol das normatizações da EAD, em agosto de 2007 é editado os RQESAD, o documento traz orientações de natureza teórico-metodológica para $\mathrm{EAD}$, as quais também se aplicam para especialização lato sensu. Vale ressaltar que a demarcação da categorização foi organizada por trechos que marcam o refinamento dos instrumentos legislativos no processo pedagógico haja vista que o referido documento não dispõe de uma estrutura especifica de lei.

Se o projeto político pedagógico é fruto, ou melhor, seu nascedouro é a comunidade escolar, há em sua elaboração um processo de diluição das normas que não fica visível, e o mesmo não é identificado como norma e muito menos como instrumentos do poder escolar. Entende-se que comunidade escolar abrange o corpo da escola (gestor, coordenação pedagógica, docentes, discentes, funcionários) e os pais dos alunos.

É dentro da unidade escolar que o fluxo de inter-relações se intensifica, de modo a naturalizar o poder arbitrário e hierárquico imbricados nesse campo. Logo, a dominação tem como âncora principal - a ação pedagógica, que revestida de poder simbólico e hierárquico atua legitimando o arbitrário cultural dominante.

Para Bourdieu apud Rosendo (2009), a ação pedagógica estar presente em todas as instâncias: escola, família, igreja, Estado, trabalho entre outros campos. A ação pedagógica é o proceder de cada instituição, refere-se ao seu fazer cotidiano, tendo como base o referencial teórico-prático norteador de suas ações. É esse fazer pedagógico que garante e promove a aceitação e inculcação do "arbitrário cultural dominante".

Rosendo (2009) segue com o pensamento de Bourdieu sobre a ação pedagógica trazer no seu cerne o arbitrário cultural dominante, de modo que, o habitus do indivíduo é influenciado pela ação pedagógica e esta por sua vez promover a incorporação do habitus dominante, garantindo sua interiorização.

Segundo Bourdieu e Passeron, toda a acção pedagógica produz uma autoridade
pedagógica, operação pela qual concretiza a sua verdade objectiva de exercício de
violência. Sem autoridade pedagógica não é possível levar-se a cabo a acção
pedagógica, pois estas detêm o direito de imposição legítima de significações. As
representações de legitimidade da acção pedagógica variaram ao longo da história.
Assim, toda a acção pedagógica deverá ter como pressuposto a autoridade pedagó
gica que exercerá um trabalho de inculcação de um arbítrio cultural. Este trabalho de
inculcação implica sempre o exercício de violência simbólica por parte da
autoridade pedagógica. (ROSENDO, 2009, pp.6-7)

A ação pedagógica, no pensamento de Bourdieu, constitui-se por meio de uma correlação de forças alicerçada na autoridade pedagógica que legítima e escamoteia a 
realidade e ao mesmo tempo garante a transmissão do "arbitrário cultural dominante." Assim a ação pedagógica atua como forma de violência simbólica, processando-se como natural, uma vez que o sujeito da ação pedagógica estar revestido da autoridade que foi designada na estrutura organizacional escolar (Rosendo, 2009).

Segundo Bourdieu e Passeron apud Souza (2012) o dominado em momento algum se sente oprimindo ou vitimado pelo processo, sua aceitação e reconhecimento é que legitima a ação pedagógica que por sua vez, perpetua a violência simbólica.

A violência simbólica é essa coerção que se institui por intermédio da adesão que o dominado não pode deixar de conceder ao dominante (portanto, à dominação), quando dispõe apenas, para pensá-lo e para pensar a si mesmo, ou melhor, para pensar sua relação com ele, de instrumentos de conhecimento partilhados entre si e que fazem surgir essa relação como natural, "pelo fato de serem, na verdade, a forma incorporada da estrutura da relação de dominação". (BOURDIEU, apud SOUZA, 2012, p.28)

A ação pedagógica é o principal veículo de poder, no qual impõe o arbitrário cultural dominante de um grupo e o legitima. O poder atribuído à autoridade pedagógica estar revestido de violência simbólica, por trata-se de uma relação hierárquica e também por estar embutida de poder arbitrário e disciplinar. Há ainda outro fator preponderante que contribui e agrega poder simbólico, garantindo e promovendo a violência simbólica, o poder conferindo a escola, na seleção de conteúdos (currículo) relevantes na formação do indivíduo, dando-lhe significações e valoração no contexto social vigente. (BOURDIEU \& PASSERON, apud CANESIN, 2002)

Nesse processo de dominação pedagógica os agentes revestidos da autoridade hierárquica concedida pelo sistema, têm papel preponderante para consolidar e transmitir o arbitrário cultural. E dessa forma a ação pedagógica por meio da violência simbólica cumpri sua função - legitimar a reprodução social.

Na organização didático-pedagógica no item "c" referente à confecção de material didático para a educação a distância revela-se como um dos instrumentos de dominação, uma vez que a confecção do mesmo fica na responsabilidade de mestres e doutores da área, porém quem vai lidar com o material é o aluno da EAD e cabe ao tutor dirimir as dúvidas dos alunos. Assim essa relação entre o professor conteúdista e o tutor (monitor do aluno) estar plasmada na dominação, no qual o poder simbólico e arbitrário do primeiro é claro sob o segundo.

[...] Nesse sentido, o professor tem um papel significativo, pois a ele também é conferido um alto grau de legitimação pela sociedade, tornando assim um agente confiável do processo de dissimulação: "os docentes constituem os produtos mais acabados do sistema de produção”. (BOURDIEU \& PASSERON, apud ALMEIDA, p.151). 
Para Teixeira (2005) o currículo escolar também é por excelência um instrumento de dominação. É na seleção de conteúdos, no qual se privilegia alguns conteúdos em detrimentos de outros, cujo poder simbólico dissimula e escamoteia as relações de dominação veiculadas na escola, por meio da ação pedagógica que permeia as relações escolares.

\footnotetext{
Dessa forma, o currículo escolar passa a ser entendido enquanto campo de implementação de práticas e políticas culturais, interferindo na produção do imaginário social e do senso comum da população, a partir dos valores, normas e padrões culturais que veicula em um espaço de produção e reprodução sociocultural. Ele possibilita à sociedade ou aos grupos sociais assegurar que seus membros se apropriem e/ou renovem as experiências sociais historicamente acumuladas; é um produto social e cultural, resultante de um processo de tradição seletiva, que envolve relações de poder que permeiam os segmentos sociais, ao definir e organizar os saberes e os conhecimentos que serão utilizados na formação dos sujeitos sociais e, por tanto, na produção de identidades individuais e coletivas particulares, em consonância com determinado projeto de sociedade. (TEIXEIRA, 2005, p.118)
}

Apesar de a legislação deflagrar um processo de dominação sistêmico, já que o mesmo se estende aos instrumentos educacionais: unidade escolar, gestão escolar, coordenação pedagógica, projeto político pedagógico, corpo docente e corpo de normas escolares, não se podem falar no processo passivo e de simples aculturamento, considerando o sujeito escolar (para designar todos envolvidos no processo de escolarização), como mero recipiente ou depósito sem capacidade de reflexão, esquecendo que há um processo dialético de construção do seu habitus.

Após, deflagrar os instrumentos de dominação referendados pela legislação de ensino da pós-graduação lato sensu (EAD) parte-se para as considerações finais.

\section{CONSIDERAÇÕES FINAIS}

A especialização lato sensu à distância circunscrita no contexto da globalização vem de encontro aos anseios de trabalhadores e estudantes que buscam nessa modalidade a especialização em áreas do saber como diferencial competitivo no atual mercado de trabalho, e também como diferencial técnico no desempenho do cargo.

Vários estudiosos da EAD consideram o art. 80 da atual LDB o marco regulatório, no qual retira a modalidade da periferia do Sistema de Ensino, garantindo a qualidade do ensino ofertado e desmitificando a inferioridade do modelo. A partir da atual norma, a especialização lato sensu $(\mathrm{EAD})$ é inserida no ordenamento jurídico que trata do ensino à distância.

Quanto à regulação dos cursos de especialização lato sensu (EAD), praticamente até, a publicação da Resolução CES/CNE Nº 01 de 2007, a modalidade era regulada em 
alguns artigos de outras normas, como no artigo 11 Resolução CNE/CES No 1/2001( revogada pela Res. CNE/CES No 01/2007) e o Decreto No 5.622/2005, cuja revogação deu-se recentemente, maio de 2017 com a edição do decreto $\mathrm{N}^{\circ}$ 9.057/2017.

Como podemos verificar ao analisar os atos normativos reguladores da EAD, a nossa Política Educacional para a EAD vai sendo construída com emendos e alinhavos para preencher as lacunas deixadas pelos atos anteriores. Não há normas sólidas, sua construção acontece à medida que são editados os atos normativos, como decretos, resoluções, portarias e entre outros. Revelando a carência em nosso ordenamento-jurídico centrado nas singularidades dessa modalidade.

Retomando a questão central do estudo referente aos instrumentos de dominação presentes na legislação que regulamenta a Especialização Lato Sensu na modalidade EAD, podemos afirmar que os instrumentos de dominação estão presentes na estrutura organizacional do nosso Sistema de Ensino (macrossistema, microssistemas e subsistemas de ensino), os quais são institucionalizados pela legislação de ensino seja ela centrada no ensino presencial ou a distância.

A legislação de ensino, seja, ela do ensino da especialização lato sensu à distância ou de qualquer nível e modalidade, por si, já é um forte instrumento de dominação, por tratar da normatização de um campo de poder - a educação. Nesse campo de poder são introduzidos via legislação os genuínos instrumentos do poder simbólico e hierárquico, uma das formas de dominação. São eles: unidade escolar, gestão democrática, projeto político pedagógico, coordenação pedagógica, corpo docente e corpo de normas escolares, entre outros.

O dialogo sobre os instrumentos dominação tem ancoragem no pensamento bourdieusiano sobre campo, habitus, campo de poder e poder simbólico.

A partir das ideias de Bourdieu é possível perceber a sinergia forte ente o campo de regulação (legislação) e o campo educacional (sistema escolar) em conjugar vários dispositivos administrativos e normativos, que por sua vez, constituídos do refinamento e validação regulatória cooptam os indivíduos, sem despertar qualquer reação de resistência.

É imprescindível esclarecer que apesar de Bourdieu conceber a escola como local privilegiado de reprodução e legitimação da cultura dominante, cuja ação se faz presente no seu fazer pedagógico e administrativo, ademais, também acredita no potencial da escola, devido sua situação de campo de poder responsável pelo conhecimento para romper as estruturas de poder dominante, possibilitando aos alunos das classes populares condições escolares que os coloquem em níveis de igualdades aos alunos das classes dominantes. 
A escola é um microssistema social, cujo processo de dominação dá-se por meio da ação pedagógica atuando como força de coesão e imbuída de consolidar e transmitir o arbitrário cultural dominante, mas não significa dizer que em virtude disso, neutralize ou paralise seu potencial de instrumento de emancipação e sua contribuição com as rupturas das estruturas dominantes.

\section{REFERÊNCIAS}

ALMEIDA, Lenildes Ribeiro da Silva. Pierre Bourdieu: A Transformação Social no Contexto de "A Reprodução" . Inter-Ação: Rev. Fac. Educ. UFG, v.30, n.1, p.139-155, jan./jun. 2005. [Documento eletrônico]. Disponível em:

<www.revistas.ufg.br/index.php/interacao/article/download/1291/1343>. Acesso em: 22 maio 2017.

ALVES, João Roberto Moreira. A história da EAD no Mundo. In LITTO, Fredric Michael \& FORMIGA, Manuel Marcos Maciel (Org.). Educação a Distância: o estado da arte. São Paulo: Peearson, 2009.

BERTOLleTI, Vanessa Alves; AZEVEDO, Mário Luiz Neves de. A Escola em Questão: uma análise a cerca da obra "A Reprodução" e do Pensamento de Pierre Bourdieu. [Documento eletrônico]. Disponível em:<

http://www.portalanpedsul.com.br/admin/uploads/2010/Sociologia_da_Educacao/Trabalho/08 _25_15_A_ESCOLA_EM_QUESTAO_UMA_ANALISE_ACERCA_DA_OBRA_ _A_REPRODUCAO_E_DO_PENSAMENTO_DE_PIERRE_BOURDIEU.PDF>. Acesso em: 22 maio 2017.

BOTLER, Alice Happ. Cultura e Relações de Poder na Escola. 2010. [Documento eletrônico]. Disponível em:<seer.ufrgs.br/educacaoerealidade/article/download/8708/9460>. Acesso em: 22 maio 2017.

BOURDIEU, Pierre. O poder simbólico. Tradução, Fernando Tomaz. Rio de Janeiro: Bertrand Brasil, 1898. (coleção memória e sociedade). [Documento eletrônico]. Disponível em:<

http://lpeqi.quimica.ufg.br/up/426/o/BOURDIEU_Pierre_O_poder_simb\%C3\%B3lico.pdf>. Acesso em: 22 maio 2017.

.Razões práticas: sobre a teoria da ação. Tradução, Mariza Correa. Campinas: São Paulo, Papirus, 1996. [Documento eletrônico]. Disponível em:< https://edisciplinas.usp.br/pluginfile.php/347738/mod_resource/content/1/BOURDIEU\%2C\% 20P.\%20Raz\%C3\%B5es\%20Pr\%C3\%A1ticas\%20$\% 20$ Sobre\%20a\%20Teoria\%20da\%20A\%C3\%A7\%C3\%A3o.pdf>. Acesso em: 22 maio 2017.

BRASIL. Presidência da República. Decreto no 5.622, de 19 de dezembro de 2005 . Regulamenta o art. 80 da Lei $n^{\circ} 9.394$, de 20 de dezembro de 1996, que estabelece as diretrizes e bases da educação nacional. [Documento eletrônico]. Disponível em: http://<portal.mec.gov.br/sesu/arquivos/pdf/portarias/dec5.622.pdf>. Acesso em: 22 maio 2017. 
Presidência da República. Decreto no 9.057, de 26 de maio de 2017. Regulamenta o art. 80 da Lei ${ }^{\circ}$ 9.394, de 20 de dezembro de 1996, que estabelece as diretrizes e bases da educação nacional. [Documento eletrônico]. Disponível em: < http://www.planalto.gov.br/ccivil_03/_ato2015-2018/2017/decreto/D9057.htm>. Acesso em: 22 maio 2017.

Presidência da República. Decreto-Lei no 236, de 38 de fevereiro de 1967. Complementa e modifica a Lei número 4.117 de 27 de agôsto de 1962/Código Brasileiro de Telecomunicações. [Documento eletrônico]. Disponível em:< http://www.planalto.gov.br/ccivil_03/decreto-lei/Del0236.htm>. Acesso em: 22 maio 2017.

. Ministério da Educação. Lei no 9.394, de 20 de dezembro de 1996. Lei de Diretrizes e Base da Educação Nacional. Estabelece as diretrizes e bases da educação nacional. 1996. [Documento eletrônico]. Disponível em: < http://portal.mec.gov.br/arquivos/pdf/ldb.pdf.>. Acesso em: 22 maio 2017.

BRASIL. Ministério da Educação. Resolução CNE/CES nº 01, 03 de abril de 2001. [Documento eletrônico]. Disponível em:< http://portal.mec.gov.br/seed/arquivos/pdf/tvescola/leis/CES0101.pdf >. Acesso em: 22 maio 2017.

Ministério da Educação. Resolução CNE/CES nº 01, 08 de junho de 2007.

Estabelece normas para pós-graduação lato sensu à distância. [Documento eletrônico]. Disponível em: < http://portal.mec.gov.br/cne/arquivos/pdf/rces001_07.pdf >. Acesso em: 22 maio 2017.

Ministério da Educação. Parecer CFE no 891, 18 de dezembro de 2002.

[Documento eletrônico]. Disponível em:<

http://www.dominiopublico.gov.br/pesquisa/DetalheObraForm.do?select_action=\&co_obra=5 0241>. Acesso em: 22 maio 2017.

Ministério da Educação. Referenciais de Qualidade para Educação Superior a

Distância. Brasília, agosto de 2007. [Documento eletrônico]. Disponível em:

$<$ http://portal.mec.gov.br/sesu/arquivos/pdf/referenciaisqualidadeead.pdf $>$. Acesso em: 22 maio 2017.

KENSKI, Vani Moreira. O Desafio da Educação a Distância no Brasil. 2010. [Documento eletrônico]. disponível em: http://www.ufjf.br/revistaedufoco/files/2010/02/011.pdf. Acesso em: 22 maio 2017.

LESSA, Shara Christina Ferreira. Os reflexos da legislação de educação a distância no Brasil. Associação Brasileira de Educação a Distância - ABED. Revista Científica, 2011. [Documento eletrônico]. Disponível em: <http://www.abed.org.br/revistacientifica/Revista_PDF_Doc/2011/Artigo_02.pdf>. Acesso em: 22 maio 2017.

MIGUEL, Maria Elisabeth Blank. A Legislação Educacional: uma das fontes de estudos para a história da educação brasileira. 2004. [Documento eletrônico]. Disponível em: $<$ http://www.histedbr.fae.unicamp.br/navegando/artigos_pdf/Maria_Elisabeth_Blanck_Mi guel_artigo.pdf $>$. Acesso em: 22 maio 2017. 
MORAES Roque. Análise de conteúdo. Revista Educação, Porto Alegre, v. 22, n. 37, p. 732, 1999. [Documento eletrônico]. Disponível em:<

http://cliente.argo.com.br/ mgos/analise_de_conteudo_moraes.html >. Acesso em: 22 maio 2017.

PENA, Rodrigo Antônio Simões da Silva. P. Bourdieu, Sociologia e Teoria da

Reprodução. As Contribuições à Discussão Curricular. [Documento eletrônico].

Disponível em:< http://www.educonufs.com.br/cdvicoloquio/eixo_17/PDF/45.pdf >. Acesso em: 22 maio 2017.

PIES, Neri Gervásio. Capital Cultural e Educação em Bourdieu. 2011. Dissertação apresentada ao Programa de Pós-Graduação em educação da Faculdade de educação. Universidade de Passo Fundo. [Documento eletrônico]. Disponível em:< www.ppgedu.upf.br/index.php?option=com_docman\&task=doc >. Acesso em: 22 maio 2017.

PRETI, Oreste. Educação à distância: fundamentos e políticas. Cuiabá : EdUFMT, 2009. [Documento eletrônico]. Disponível em:

<http://www.uab.ufmt.br/uab/images/livros_download/fundamentos_e_politicas.pdf >. Acesso em: 22 maio 2017.

SALVUCCI, Mara. LISBOA, Marcos J. A. MENDES, Nelson C. Educação a Distância no Brasil: Fundamentos legais e implementação. Revista Brasileira de Aprendizagem Aberta e a Distância. V.1. ABED, São Paulo: 2012. [Documento eletrônico]. Disponível em:< http://www.abed.org.br/revistacientifica/Revista_PDF_Doc/2012/artigo_04_v112012.pdf.>. Acesso em: 22 maio 2017.

SLAVOV, Bárbara; SLAVOA, Ricardo. Educação a Distância, uma nova modalidade de ensino e a legislação brasileira. Revista Sapere - Revista Científica da Faculdade de Tecnologia de Tatuí. V2,N1,Tatuí:2010. [Documento eletrônico]. Disponível em: <http://www.revistasapere.inf.br/download/segunda/SLAVOV_SLAVOV.pdf.>. Acesso em: 22 maio 2017.

SOUZA, Liliane Pereira. A Violência Simbólica na Escola: Contribuições de Sociólogos Franceses ao Fenômeno da Violência Escolar Brasileira. Revista LABOR, nº 7, v.1, 2012. [Documento eletrônico]. Disponível em:<http://www.revistalabor.ufc.br/Artigo/volume7/2_A_violencia_simbolica_na_escola__Liliane_Pereira.pdf>. Acesso em: 22 maio 2017.

TEIXEIRA, Célia Regina. Currículo escolar: um caso de dominação e reprodução social? Um breve esboço. Dialogia, São Paulo, 2005. [Documento eletrônico]. Disponível em:< http://www.uninove.br/PDFs/publicacoes/dialogia/dialogia_v4/dialogv4_4f.pdf $>$. Acesso em: 22 maio 2017.

VALLE, Lílian; SOUZA, Sónia Ribeiro. EAD: políticas públicas de qualidade? [ Documento eletrônico ]. Disponível em: <http://www.utp.br/Cadernos_de_Pesquisa/pdfs/cad_pesq13/3_ead_cp13.pdf. >. Acesso em: 22 maio 2017. 